\title{
UJI PENDAHULUAN FITOKIMIA DAN ANTIOKSIDAN TUMBUHAN OBAT SUKU DAYAK DI DESA PETANGIS, KABUPATEN PASER, KALIMANTAN TIMUR
}

\author{
Septina Asih Widuri*, Noorcahyati, Ike Mediawati \\ Balai Penelitian dan Pengembangan Teknologi Konservasi Sumber Daya Alam \\ J1. Soekarno Hatta KM.38 PO.BOX 578 Balikpapan 76112, Kalimantan Timur \\ Telp.(0542)7217663 \\ *Corresponding author email: sa.widuri@yahoo.com
}

\begin{abstract}
ABSTRAK
Antioksidan diketahui dapat mencegah penyakit akibat kerusakan oksidatif oleh radikal bebas. Meskipun antioksidan sintetis tersedia secara komersial, tetapi tingkat toksisitasnya menjadi masalah. Oleh sebab itu penelitian untuk memperoleh sumber-sumber baru antioksidan yang potensial dari tumbuhan tetap diperlukan. Penelitian ini bertujuan mengetahui senyawa metabolit sekunder dan aktivitas antioksidan dari sejumlah tumbuhan hutan yang digunakan sebagai obat tradisional oleh Suku Dayak di Desa Petangis, Kabupaten Paser, Kalimantan Timur. Sampel tumbuhan yang digunakan antara lain kulit batang Guioa pterorhachis, akar Flagellaria indica, akar Nauclea officinalis, dan akar Clerodendrum adenophysum. Skrining awal fitokimia dari ekstrak etanol sampel menunjukkan adanya kandungan flavonoid, tanin, saponin, dan triterpenoid. Uji penghambatan radikal bebas menggunakan metode DPPH menunjukkan bahwa ekstrak etanol kulit batang Guioa pterorhachis memiliki nilai $\mathrm{IC}_{50}$ lebih kecil dari 7,8 ppm dan akar Nauclea officinalis memiliki nilai $\mathrm{IC}_{50} 43,7 \mathrm{ppm}$. Aktivitas antioksidan kedua tumbuhan tersebut tergolong kuat sedangkan akar Flagellaria indica dan akar Clerodendrum adenophysum tidak aktif sebagai antioksidan karena menghasilkan nilai $\mathrm{IC}_{50}$ lebih dari 200 ppm.
\end{abstract}

Kata kunci: Guioa pterorachis, Flagellaria indica, Nauclea officinalis, Clerodendrum adenophysum, antioksidan

Submitted on: 4 April $2017 \quad$ Accepted on: 17 May 2017

DOI: https://doi.org/10.25026/jsk.v1i6.55

\section{PENDAHULUAN}

Tingkat kematian akkibat penyakit degeneratif seperti diabetes, kanker, arterosklerosis dan stroke terus meningkat [1], [2], [3]. Penyakit ini antara lain disebabkan oleh kerusakan sel, jaringan maupun organ tubuh akibat radikal bebas. Radikal bebas adalah atom atau molekul yang mengandung elektron yang tidak berpasangan pada orbital terluarnya. Radikal bebas bersifat tidak stabil dan sangat reaktif terhadap molekul di sekitarnya sehingga memicu reaksi berantai untuk mencapai kestabilan. Akibat reaksi tersebut dihasilkan senyawa yang tidak normal dan menyebabkan kerusakan sel-sel dalam tubuh [4].
Antioksidan merupakan substansi yang mampu mencegah atau memperlambat terjadinya proses oksidasi akibat radikal bebas. Selain itu, antioksidan juga diperlukan untuk mempertahankan mutu produk industri pangan serta sebagai bahan penyusun produk-produk anti penuaan di industri kosmetika. Antioksidan berdasarkan sumbernya dibagi menjadi dua yaitu antioksidan alami dan antioksidan sintetik. Antioksidan sintetik memiliki kelemahan yaitu bersifat toksik [5], sedangkan antioksidan alami lebih aman digunakan. Oleh sebab itu, antioksidan alami yang bersumber dari tumbuhan sangat diperlukan. Antioksidan yang digunakan saat ini banyak bersumber dari 
buah-buahan maupun sayur-mayur sedangkan sumber yang berasal dari tumbuhan hutan masih sedikit dilaporkan. Penelitian ini bertujuan mengetahui beberapa senyawa kimia dan aktivitas antioksidan dari ekstrak etanol bagian tertentu tumbuhan obat yang digunakan oleh Suku Dayak di Desa Petangis, Kabupaten Paser, Kalimantan Timur. Suku Dayak yang tinggal di sekitar hutan di Desa Petangis ini, terutama para generasi tua umumnya masih memiliki pengetahuan tumbuhan obat dari hutan. Berdasarkan informasi tersebut, dilakukan inventarisasi tumbuhan obat dan skrining fitokimia dan uji aktivitas antioksidan dari sampel yang dipilih. Kegiatan ini merupakan pengumpulan data awal untuk penelitian dan pengembangan sumber antioksidan dan sumber obat lainnya.

\section{METODE PENELITIAN}

1. Lokasi penelitian, alat dan bahan

Lokasi pengambilan sampel tumbuhan adalah Desa Petangis, Kecamatan Batu Engau, Kabupaten Paser, Kalimantan Timur. Pengambilan sampel dilakukan pada September 2014. Alat yang digunakan antara lain kamera, GPS, alat tulis, plastik spesimen, plastik sampel, dan peralatan laboratorium. Bahan yang digunakan adalah kulit batang Guioa pterorhachis, akar Flagellaria indica, akar Nauclea officinalis, akar Clerodendrum adenophysum, aquades, kloroform, pereaksi Meyer dan Dragendorf, $\mathrm{H}_{2} \mathrm{SO}_{4}$ $2 \mathrm{M}, \mathrm{FeCl}_{3} 1 \%, \mathrm{NH}_{4} \mathrm{OH} 1 \mathrm{M}$, eter, etanol $70 \%$, DPPH, dan vitamin C.

\section{Ekstraksi sampel tumbuhan}

Bagian tumbuhan dicuci pada air mengalir dan dikeringkan pada suhu ruang lalu dihaluskan dengan blender kemudian diayak dengan ayakan 65 mesh. Ekstraksi sampel dilakukan dengan cara maserasi menggunakan pelarut etanol $70 \%$ dengan perbandingan 1:5 (sampel dan pelarut) selama 24 jam dalam suhu ruang (Sukandar et al., 2009). Ekstrak etanol selanjutnya dipekatkan dengan rotary evaporator dan hasilnya digunakan untuk pengujian selanjutnya.

3. Skrining fitokimia

Skrining fitokimia meliputi alkaloid, flavonoid, saponin dan dilakukan dengan metode standar menurut Harborne (1987) [7]. Uji alkaloid dilakukan dengan cara sebanyak $1 \mathrm{~g}$ ekstrak dilarutkan dalam $10 \mathrm{ml}$ kloroform dan 4 tetes $\mathrm{NH}_{4} \mathrm{OH}$, kemudian disaring dan filtrat yang diperoleh dimasukkan dalam tabung reaksi bertutup. Ekstrak kloroform dalam tabung reaksi dikocok dengan $6 \mathrm{ml}$ $\mathrm{H}_{2} \mathrm{SO}_{4} 2 \mathrm{M}$. Lapisan asam yang terbentuk kemudian diteteskan pada lempeng tetes lalu ditambahkan pereaksi Mayer dan Dragendorf. Endapan berwarna krem untuk pereaksi Mayer dan coklat kemerahan untuk pereaksi Dragendorf menunjukkan hasil positif. Uji flavonoid dilakukan sebagai berikut, sebanyak $0,5 \mathrm{~g}$ ekstrak dikocok dengan eter. Residu dilarutkan dengan $20 \mathrm{ml}$ etanol lalu disaring. Satu bagian filtrat ditambah dengan $5 \mathrm{ml}$ larutan amonia dan dilanjutkan dengan menambahkan $1 \mathrm{ml}$ larutan asam sulfat pekat. Hasil positif ditunjukkan dengan terbentuknya warna kuning. Uji saponin dilakukan dengan cara sebagai berikut, sebanyak $0,5 \mathrm{~g}$ ekstrak ditambah $5 \mathrm{ml}$ aquades dimasukkan dalam tabung reaksi tertutup kemudian dikocok selama 10 detik lalu didiamkan selama 10 menit. Saponin ditunjukkan dengan terbentuknya buih yang stabil pada sampel. Uji tanin dilakukan dengan cara sebagai berikut, sebanyak $0,5 \mathrm{~g}$ ekstrak ditambah $10 \mathrm{ml}$ air dan dididihkan selama 5 menit 
kemudian disaring. Filtrat yang diperoleh ditambah larutan $\mathrm{FeCl}_{3} 1 \%$. Hasil positif ditunjukkan dengan terbentuknya warna hitam kehijauan.

\section{Uji aktivitas antioksidan}

Uji aktivitas antioksidan dilakukan dengan metode spektofotometri [7]. Sumber radikal bebas yang digunakan adalah 1,1-difenil-2-pikrilhidrazil (DPPH). Analisis pengujian dilakukan dengan melihat perubahan warna masingmasing sampel setelah diinkubasi dengan DPPH. Elektron pada DPPH akan berpasangan dengan elektron pada sampel sehingga terjadi perubahan warna sampel mulai dari ungu tua hingga kuning terang. Selanjutnya absorbansi larutan sampel diukur dengan spektrofotometer $\mathrm{Uv}-\mathrm{Vis}$ pada panjang gelombang maksimum $517 \mathrm{~nm}$.

\section{HASIL DAN PEMBAHASAN}

\section{Skrining fitokimia}

Sampel pengujian adalah tumbuhan yang dimanfaatkan sebagai obat oleh Suku Dayak di Desa Petangis, Paser, Kalimantan Timur. Deskripsi serta penggunaan keempat jenis tumbuhan tersebut dapat dilihat pada Tabel 1.

Masyarakat setempat umumnya mengaplikasikan tumbuhan obat berdasarkan pengalaman tanpa mengetahui jenis senyawa kimia yang terdapat dalam suatu tumbuhan. Berdasarkan Tabel 1, tiga dari empat sampel tumbuhan diaplikasikan dengan cara meminum air rebusan simplisia. Hal ini perlu mendapat perhatian serius karena pada umumnya dosis yang digunakan masyarakat bukan berdasarkan penelitian sehingga meskipun tumbuhan tersebut memiliki khasiat obat tetapi jika dikonsumsi dengan dosis yang salah bisa menyebabkan efek samping yang berbahaya. Melalui skrining fitokimia, jenis senyawa dalam suatu tumbuhan dapat diketahui sehingga dapat diteliti lebih lanjut mengenai keamanan suatu tumbuhan untuk digunakan sebagai obat. Skrining ini juga penting sebagai data awal untuk mengetahui potensi bioaktif yang dimiliki oleh suatu tumbuhan dalam kaitannya dengan pengembangan sumber bahan obat-obatan. Sebanyak empat sampel tumbuhan obat yang diekstraksi dengan etanol telah diuji untuk mengetahui ada tidaknya senyawa metabolit sekunder seperti alkaloid, flavonoid, tanin dan saponin. Hasil analisis tersaji pada Tabel 2.

\section{a. Guioa pterorhachis Welzen}

Metabolit sekunder yang terdapat dalam ekstrak kulit batang Mangkulitai bini (Guioa pterorhachis) sebagaimana tersaji pada Tabel 2 yaitu flavonoid, tanin, saponin dan triterpenoid, sedangkan senyawa alkaloid tidak terdeteksi. Kulit batang tumbuhan ini digunakan secara tradisional sebagai obat memar atau bengkak. Fungsi ini dapat disebabkan oleh adanya senyawa flavonoid dan tanin sebagaimana dilaporkan oleh Mohammed et al. (2014) [8], bahwa golongan senyawa flavonoid dan tanin mampu menghambat sejumlah molekul target dalam proses pembengkakan jaringan. Sementara itu, Pushpangadan et al. (2015) menyebutkan sejumlah senyawa bioaktif yang digunakan sebagai antinflamasi merupakan senyawa-senyawa terpenoid seperti celastrol, wilforlide A, dan madecassoside. Kulit batang Guioa pterorhachis digunakan secara topikal pada memar [9]. Meskipun tidak dikonsumsi, penggunaan jenis tumbuhan ini sebagai obat perlu dikaji lebih lanjut karena belum ada penelitian Guioa pterorhachis dan bioaktivitasnya sebagai antiinflamasi. 
Uji Pendahuluan Fitokimia dan Antioksidan Tumbuhan Obat Suku Dayak di Desa Petangis, Kabupaten Paser, Kalimantan Timur

Tabel 1. Deskripsi empat tumbuhan obat yang digunakan Suku Dayak di Desa Petangis, Paser

\begin{tabular}{|c|c|c|c|}
\hline Species (Famili) & $\begin{array}{l}\text { Bagian yang } \\
\text { digunakan }\end{array}$ & Deskripsi tumbuhan & $\begin{array}{l}\text { Khasiat dan cara } \\
\text { penggunaan }\end{array}$ \\
\hline $\begin{array}{l}\text { Guioa pterorhachis } \\
\text { Welzen } \\
\text { (Sapindaceae) }\end{array}$ & Kulit batang & $\begin{array}{l}\text { Semak hingga pohon dengan tinggi } 3-16 \mathrm{~m} \text {, } \\
\text { diameter batang } 10 \mathrm{~cm} \text { sampai } 1,15 \mathrm{~m} \text {. Pohon } \\
\text { dewasa memiliki permukaan cabang yang halus } \\
\text { atau licin. Kayunya dimanfaatkan sebagai kayu } \\
\text { bakar. }\end{array}$ & $\begin{array}{l}\text { Mengobati bengkak } \\
\text { atau memar } \\
\text { (antiinflamasi). } \\
\text { Caranya dengan } \\
\text { merendam kulit } \\
\text { batang kemudian } \\
\text { dihaluskan lalu } \\
\text { ditempelkan pada } \\
\text { luka memar. }\end{array}$ \\
\hline $\begin{array}{l}\text { Flagellaria indica } \\
\text { (Flagellariaceae) }\end{array}$ & akar & $\begin{array}{l}\text { Tumbuhan merambat yang hidup di wilayah } \\
\text { tropis dan subtropis, tingginya bisa mencapai } 15 \\
\mathrm{~m} \text {, batangnya tebal menyerupai tebu dengan } \\
\text { diameter sekitar } 15 \mathrm{~mm} \text {. Daunnya licin dengan } \\
\text { panjang antara } 10 \text { sampai } 40 \mathrm{~cm} \text { dan lebar antara } \\
5 \text { sampai } 20 \mathrm{~mm} \text {. Ujung daun yang bergelung } \\
\text { membentuk semacam penahan bagi tumbuhan } \\
\text { untuk merambat. Bunga putih yang harum } \\
\text { terbentuk pada bagian malai sepanjang } 10 \\
\text { sampai } 25 \mathrm{~cm} \text {. Buahnya tidak bisa dimakan, } \\
\text { bijinya berwarna merah kehijauan dengan } \\
\text { diameter } 5 \mathrm{~mm} \text {, umumnya terdiri dari satu biji } \\
\text { saja. }\end{array}$ & $\begin{array}{l}\text { Suplemen penambah } \\
\text { stamina. Caranya } \\
\text { dengan merebus akar } \\
\text { kemudian air rebusan } \\
\text { diminum. }\end{array}$ \\
\hline Nauclea officinalis & akar & $\begin{array}{l}\text { Tinggi pohon bisa mencapai } 33 \text { m dengan } \\
\text { diameter } 67 \mathrm{~cm} \text {. Panjang stipula } 10 \mathrm{~cm} \text { dengan } \\
\text { ujung membulat. Daunnya terletak berlawanan, } \\
\text { permukaan daun licin. Bunga diameter } 3 \mathrm{~cm} \\
\text { berwarna kekuningan. Buah berdiameter } 16 \mathrm{~mm} \\
\text { berwarna hijau-kuning kecoklatan, menyatu } \\
\text { pada tubuh buah. Habitatnya di hutan campuran } \\
\text { dipterokarpa dan keranga dengan ketinggian 0- } \\
600 \text { mdpl. Kayunya digunakan untuk kayu } \\
\text { konstruksi, ukiran dan furnitur. Tersebar di } \\
\text { wilayah Cina Selatan, Indocina, Thailand, } \\
\text { Semenanjung Malaysia, Sumatera, Borneo. }\end{array}$ & $\begin{array}{l}\text { Disentri caranya } \\
\text { dengan meminum air } \\
\text { rebusan akar, memar } \\
\text { dengan cara } \\
\text { ditumbuk lalu } \\
\text { ditempel pada } \\
\text { memar. }\end{array}$ \\
\hline $\begin{array}{l}\text { Clerodendrum } \\
\text { adenophysum }\end{array}$ & akar & $\begin{array}{l}\text { Tumbuhan bawah yang tingginya mencapai } 11 \\
\text { m dan diameter } 13 \mathrm{~cm} \text {. Tidak terdapat stipula. } \\
\text { Daun berlawanan, pada umumnya licin } \\
\text { permukaannya, pangkal daun berbentuk hati. } \\
\text { Bunga berdiameter } 17 \mathrm{~cm} \text { berwarna putih merah } \\
\text { muda dengan daun mahkota. Buahnya } \\
\text { berdiameter } 7 \mathrm{~mm} \text {, warnanya hujau dan berbiji. } \\
\text { Hidup pada hutan sekunder campuran } \\
\text { dipterokarpa, pesisir hingga gunung. } \\
\text { Ketinggiannya bervariasi antara } 0-1500 \mathrm{~m} \text {. } \\
\text { Biasanya tumbuh pada tepi jalan, sungai dan } \\
\text { aliran pada tanah berpasir hingga tanah liat } \\
\text { tetapi juga batuan kapur. }\end{array}$ & $\begin{array}{l}\text { Disentri caranya } \\
\text { dengan meminum air } \\
\text { rebusan akar. }\end{array}$ \\
\hline
\end{tabular}


Uji Pendahuluan Fitokimia dan Antioksidan Tumbuhan Obat Suku Dayak di Desa Petangis, Kabupaten

Paser, Kalimantan Timur

Tabel 2. Senyawa metabolit sekunder dalam ekstrak etanol sampel tumbuhan obat yang digunakan Suku Dayak Paser

\begin{tabular}{|c|c|c|c|c|c|c|c|}
\hline No. & Nama latin & $\begin{array}{l}\text { Bagian } \\
\text { tumbuhan }\end{array}$ & Alkaloid & Flavonoid & Tanin & Saponin & Triterpenoid \\
\hline 1 & $\begin{array}{l}\text { Mangkulitai bini (Guioa } \\
\text { pterorhachis } \text { Welzen) }\end{array}$ & $\begin{array}{l}\text { Kulit } \\
\text { batang }\end{array}$ & - & + & + & + & + \\
\hline 2 & $\begin{array}{l}\text { Rotan awoy (Flagellaria } \\
\text { indica) }\end{array}$ & akar & - & + & - & - & - \\
\hline 3 & $\begin{array}{l}\text { Kayu kuning (Nauclea } \\
\text { officinalis) }\end{array}$ & akar & - & + & + & + & + \\
\hline 4 & $\begin{array}{l}\text { Bontas alang (Clerodendrum } \\
\text { adenophysum Halliewr.F.) }\end{array}$ & akar & - & - & - & + & + \\
\hline
\end{tabular}

Tabel 3. Nilai konsentrasi penghambatan DPPH 50\% dari ekstrak etanol sampel tubuhan obat yang digunakan Suku Dayak di Desa Petangis Kabupaten Paser

\begin{tabular}{lcc}
\hline Nama Tumbuhan & Hasil (ppm) & Kategori \\
\hline Mangkulitai bini (Guioa pterorhachis Welzen) & $<7.8$ & sangat kuat \\
Rotan awoy (Flagellaria indica) & $>500$ & tidak aktif \\
Kayu kuning (Nauclea officinalis) & 43.7 & sangat kuat \\
Bontas alang (Clerodendrum adenophysum Halliewr.F.) & 205 & tidak aktif \\
Kontrol (Vitamin C) & 2.2 & \\
\hline
\end{tabular}

b. Kategori berdasarkan Badarinath (2010) [4].

\section{c. Flagellaria indica}

Tumbuhan ini dikenal oleh masyarakat Petangis dengan nama rotan awoy. Rebusan akar tumbuhan ini digunakan Suku Dayak di Desa Petangis sebagai minuman penambah stamina. Flagellaria indica juga dimanfaatkan secara tradisional untuk peluruh seni atau diuretik dan sebagai tonik kesehatan, rebusan daunnya untuk obat obat asma, air infus tangkai untuk mengobati diare dan disentri [10]. Mengkonsumsi batangnya dapat menyebabkan infertilitas sehingga digunakan sebagai kontrasepsi alami. Berdasarkan analisis fitokimia yang tersaji pada Tabel 2, ekstrak etanol akar Flagellaria indica hanya mengandung senyawa flavonoid. Kajian lebih dalam mengenai toksisitas dan dosis aman dari sampel perlu dilakukan sebab pemanfaatan tumbuhan ini dilakukan dengan cara meminum air rebusan akar.

\section{d. Nauclea officinalis}

Akar tumbuhan yang dikenal dengan nama kayu kuning ini dimanfaatkan oleh Suku Dayak di Desa Petangis sebagai obat disentri dengan cara meminum air rebusannya. Sebagaimana tersaji dalam Tabel 2, senyawa yang terdapat dalam ekstrak akar tumbuhan ini antara lain flavonoid, tanin, saponin dan triterpenoid. Khasiat tumbuhan ini sebagai obat disentri dapat dikaitkan dengan bioaktivitas antibakteri dari senyawa tannin [11] dan didukung pula oleh keberadaan senyawa flavonoid yang berperan dalam aktivitas antimikroba dan antivirus. Berdasarkan Tabel 1, pemanfaatan tumbuhan ini terutama kayunya adalah sebagai bahan konstruksi, ukiran dan furniture. Pemanfaatan Nauclea officinalis sebagai tumbuhan obat perlu dikaji lebih jauh. 


\section{e. Clerodendrum adenophysum}

Bontas alang atau Clerodendrum adenophysum adalah tumbuhan bawah yang akarnya digunakan untuk mengobati disentri. Ekstrak akar tumbuhan ini mengandung senyawa saponin dan triterpenoid. Saponin secara tradisional telah banyak digunakan sebagai deterjen, pestisida, dan moluscisida.

\section{Aktivitas antioksidan}

Aktivitas antioksidan dari ekstrak etanol sampel tumbuhan obat diukur dengan metode DPPH. Metode ini digunakan karena sederhana, cepat, sensitif, dan dapat reprodusibel [12]. Pengujian ini dilakukan dengan cara mengukur penangkapan radikal sintetik yaitu DPPH dalam pelarut polar. Senyawa DPPH yang stabil berwarna ungu dan jika tereduksi akan berubah warna menjadi kuning [13]. Prinsip dari metode ini adalah penangkapan elektron bebas dari senyawa donor. Tujuan metode ini adalah untuk mengetahui parameter konsentrasi yang ekuivalen memberikan $50 \%$ efek aktivitas antioksidan. Aktivitas antioksidan ekstrak sampel tumbuhan obat dinyatakan dalam nilai $\mathrm{IC}_{50}$ (Inhibitory Concentration). Nilai $\quad \mathrm{IC}_{50}$ menggambarkan besarnya konsentrasi senyawa uji yang dapat menangkap radikal sebesar 50\%. Semakin kecil nilai $\mathrm{IC}_{50}$ maka senyawa uji tersebut semakin efektif sebagai penangkap radikal bebas. Nilai konsentrasi penghambatan DPPH sebesar 50\% dari ekstrak etanol sampel tumbuhan obat dapat dilihat pada Tabel 3.

Beberapa jurnal menyebutkan kategori kekuatan aktivitas antioksidan berdasarkan nilai $\mathrm{IC}_{50}$. Ariyanto menyebutkan bahwa suatu senyawa dikategorikan sangat aktif sebagai antioksidan jika nilai $\mathrm{IC}_{50}$ yang dimiliki $\leq$
$50 \mathrm{ppm}$, berpotensi sedang jika nilai $\mathrm{IC}_{50}$ berkisar 100-200 ppm dan tidak aktif sebagai antioksidan jika nilai $\mathrm{IC}_{50}>200$ ppm. Badarinath (2010) menyatakan bahwa suatu senyawa dikatakan sebagai antioksidan sangat kuat jika nilai $\mathrm{IC}_{50}$ kurang dari 50 ppm, kuat jika nilai $\mathrm{IC}_{50}$ antara 50-100 ppm, sedang jika nilai $\mathrm{IC}_{50}$ antara $100-150 \mathrm{ppm}$, lemah jika nilai $\mathrm{IC}_{50}$ antara 151-200 ppm dan tidak aktif sebagai antioksidan jika nilai $\mathrm{IC}_{50}$ lebih dari 200 ppm [14].

Berdasarkan hasil yang tersaji pada Tabel 3, ekstrak etanol dari kulit batang Guioa pterorhachis dan akar Nauclea officinalis menghasilkan aktivitas antioksidan yang sangat kuat sedangkan ekstrak akar Flagellaria indica dan akar Clerodendrum adenophysum tergolong tidak aktif sebagai antioksidan.

Berdasarkan Tabel 2, G. pterorhachis dan N. officinalis mengandung senyawa flavonoid dan tanin sehingga aktivitas antioksidan kedua jenis tumbuhan ini lebih kuat dibanding $F$. indica yang hanya mengandung senyawa flavonoid maupun C. adenophysum yang tidak memiliki flavonoid maupun tanin. Hal tersebut diduga karena flavonoid dan tanin merupakan golongan utama antioksidan [6]. Ketidak aktifan akar $F$. indica juga dapat disebabkan oleh rendahnya kadar flavonoid dalam ekstrak etanol yang diuji. Hal ini dapat dipengaruhi oleh penggunaan etanol dalam proses ekstraksi maupun konsentrasinya. Menurut Boeing et al., etanol merupakan pelarut polar tetapi tidak lebih polar dari pada metanol sehingga senyawa fenolik yang bersifat polar akan lebih terlarut pada methanol [15]. Jika senyawa fenolik yang diperoleh kecil maka kemungkinan antioksidan yang diperoleh juga kecil. Gnanaraj melaporkan bahwa daun $F$. 
indica yang diekstrak dengan beberapa jenis pelarut menunjukkan aktivitas antioksidan yang tergolong kuat. Dalam laporan tersebut juga disebutkan bahwa ekstrak butanol menghasilkan aktivitas antioksidan tertinggi dan total komponen flavonoid tertinggi dibanding pelarut etil asetat, kloroform maupun metanol. Struktur flavonoid memungkinkan senyawa ini mengikat radikal bebas [17]. Flavonoid bekerja sebagai antioksidan dalam berbagai mekanisme, di antaranya dengan transfer atom hidrogen atau donasi elektron atau berinteraksi dengan antioksidan yang lain [16]. Senyawa lain yang menunjukkan aktivitas antioksidan adalah tannin [19] dan saponin. Sejumlah laporan menyebutkan bahwa saponin yang diisolasi dari tumbuhan memiliki berbagai aktivitas biologis seperti antikanker, menurunkan kadar kolesterol, menurunkan kadar gula darah, meningkatkan daya tahan tubuh dan sebagai antioksidan. Ekstrak etanol akar $C$. adenophysum yang diuji dalam penelitian ini menunjukkan adanya saponin tetapi tidak cukup menghasilkan aktivitas antioksidan yang kuat. Jenis pelarut diduga mempengaruhi kuantitas total saponin yang dihasilkan.

\section{KESIMPULAN}

Tumbuhan obat yang digunakan Suku Dayak di Desa Petangis Kabupaten Paser (Guioa pterorhachis, Flagellaria indica, Nauclea officinalis, dan Clerodendrum adenophysum) memiliki sejumlah metabolit sekunder seperti flavonoid, tanin, saponin dan triterpenoid. Ekstrak etanol kulit batang $G$. pterorhachis dan ekstrak akar $N$. officinalis menghasilkan aktivitas antioksidan yang kuat pada pengujian penghambatan radikal bebas menggunakan DPPH sedangkan ekstrak akar $F$. indica dan ekstrak akar $C$. adenophysum tidak aktif sebagai antioksidan.

\section{UCAPAN TERIMA KASIH}

Penulis mengucapkan terima kasih pada Balai Penelitian Teknologi Konservasi Sumber Daya Alam, Laboratorium Biofarmaka IPB dan seluruh anggota tim pelaksana penelitian (Bina Swasta Sitepu, Zaenal Arifin, Yusub Wibisono) dan Bapak Jeno sebagai narasumber tumbuhan obat di Desa Petangis, Paser.

\section{DAFTAR PUSTAKA}

[1]. Devasagayam T. P. A., J. C. Tilak, K. K. Boloorl. 2004. Review: Free Radical and Antioxidants in Human Health. Curr Stat Fut Pros JAPI. 53: 794-804.

[2]. Nag, Anish., M. Bandyopadhyay., A. Mukherjee. 2013. Antioxidant Activities and Cytotoxicity of Zingiber zerumbet (L.) Smith Rhizome. Journal of Pharmacognosy and Phytochemistry 2(3): 102-108.

[3]. Patel, V.R., P.R. Patel, S.S. Kajal. 2010. Antioxidant Activity of Some Selected Medicinal Plants in Western Region of Indian. Advances in Biological Research 4(1): 23-26.

[4]. Badarinath, A.V., K.M. Rao, C.M.S. Chetty, S. Ramkanth, T.V.S. Rajan, K. Gnanaprakash. 2010. A Review on InVitro Antioxidant Methods: Comparisions, Correlations and Considerations. International Journal of PharmaTech Research, 2(2): 1276-1285.

[5]. Shui, G. H., Leong L. P. 2004. Analysis of Polyphenolic Antioxidants Activity of Methanolic Leaves and Flowers Extracts of Lippia alba. Research Journal of Medicine and Medical Agencies. 4(1):107110.

[6]. Harborne, J. B. \& C. A. Williams. 2000. Advances in Flavonoid Research Since 1992. Phytochemistry. 55:481-504.

[7]. Leu, S.J., Y.P. Lin, R.D. Lin, et al. 2006. Phenolic Constituents of Malus doumeri var formosana in the Field of Skin Care. Biological and pharmaceutical Bulletin, Vol.29(4):740-745. 
[8]. Mohammed, M.S., W.J.A. Osman, E.A.E. Garelnabi, Z. Osman. B. Osman. H.S. Khalid, M.A. Mohamed. 2014. Secondary Metabolites as Anti-inflammatory Agents. The Journal of Phytopharmacology 3(4):275-285.

[9]. Pushpangadan, P., T.P. Ijniu, V. George. 2015. Plant Based Anti-inflammatory Secondary Metabolites. Review. Annals of Phytomedicine 4(1): 17-36.

[10]. Anonim.http://tropical.theferns.info/viewtr opical.php?id=Flagellaria+indicahttp://ww w.asianplant.net/Rubiaceae/Nauclea_offici nalis.htm

[11]. Ajizah, A. 2004. Sensitivitas Salmonella typhium terhadap Ekstrak Daun Jambu Biji. Bioscientiae. (1)1.

[12]. Savatovic, S.M., G.S. Cetkovic, J.M. Canadonovic-Brunet, S.M. Djilas. 2012. Kinetic Behaviour of the DPPH Radical Scavenging Activity of Tomato Waste Extracts. Journal of Serbian Chemical Society. 77: 1-12.

[13]. Prakash, A., F. Rigelhof, E. Miller. 2001. Antioxidant Activity. Medallion Laboratories-Analytical Progress. 19(2): 14.

[14]. Ariyanto, R. 2006. Uji Aktivitas Antioksidan, Penentuan Kandungan Fenolik dan Flavonoid total Fraksi Kloroform dan Fraksi Air Ekstrak Metanolik Pegagan (Centella asiatica L. Urban), Skripsi. Fakultas Farmasi Universitas Gadjah Mada.
[15]. Boeing, J.S., E.O. Barizao, B.C.E. Silva, P.F. Montanher, V.D.C. Almeida, J.V. Visentainer. 2014. Evaluation of Solvent Effect on the Extraction of Phenolic Compounds and Antioxidant Capacities from the Berries: Application of Principal Component Analysis. Chemistry Central Journal 8(48): 1-9.

[16]. Bombardelli, E. \& P. Morazzoni. 1993. The Flavonoids: New Perspectives in Biological Activities and Therapeutics. Chimicaoggi. 25-28.

[17]. Gnanaraj, C., M.D. Shah, A.T.M.E.M. Haque, M. Iqbal. 2015. Phytochemical Screening, Antioxidant Properties in Various Extracts from the Leaves of Flagellaria indica L. from Sabah, Malaysia. International Journal of Pharmacy and Pharmaceutical Sciences 7(9):510-512.

[18]. Sukandar, E.Y., R. Andrajati, J.I. Sigit, I.K. Adnyana, A.P. Setiadi, Kusnandar. 2009. ISO Pharmacotherapy. Penerbit PT. ISFI. Jakarta.

[19]. Zhang, S. J., Y. M. Lin, H. C. Zhou, S. D. Wei, G. H. Lin \& G. F. Ye. 2010. Antioxidant Tannins from Stem Bark and Fine Root of Casuarina equisetifolia. Molecules. 15:5658-5670. 